\title{
CUANDO EL AMOR TERMINA, LA FICCIÓN COMIENZA
}

WHEN LOVE ENDS, FICTION STARTS

Julia Musitano

ORCID 0000-0001-6638-6207

Universidad Nacional de Rosario - CONICET

Rosario, Santa Fe, Argentina

Ariza, Julio. El abandono. Abismo amoroso y crisis social en la literatura argentina reciente, Rosario: Beatriz Viterbo, 2018, 236p.

La revista Anfibia publicó a principios de este año un número en papel sobre el amor: relatos de escritores y críticos literarios argentinos sobre amor. En todos sus colores y formas, cada página derrocha ternura, felicidad y tristeza como despliegues del mismo tema. El tema del amor: encuentro y reencuentro infinito, desencuentros inapelables, cuerpos hastiados, incertidumbre desafiante, pasión y frialdad, virtualidad y realidad. Me alegró mucho ver un número entero dedicado al tema, y más me alegró cuando la editorial Beatriz Viterbo me acercó un libro publicado este mismo año para reseñar: El abandono de Julio Ariza. Embarcada en el tren de los encuentros amorosos, me escapé por el vagón trasero del desengaño, de la crisis, de la vulnerabilidad del abandono.

Podríamos decir que el amor es el gran tema de la novela, en principio, y después agregar que de la literatura en general. Podríamos también preguntarnos si la literatura argentina se ha dedicado a escribir sobre amor, ¡cuáles son los textos canónicos que lo sondean, que, al menos, lo miran de refilón? Y responder que los contamos con los dedos de una mano. ¿̇acedonio Fernández, Leopoldo Marechal, Manuel Puig? A pesar de eso, Ariza pudo armar una serie literaria con un solo casillero del calendario amoroso: el del abandonado.

Escribir de o sobre el amor pone en escena la experiencia amorosa, pero la diferencia reside en que uno cuenta como clase y el otro se despliega en una serie. Esa es la gran propuesta de Ariza: entrar a la literatura de una serie de escritores actuales de la literatura argentina (Daniel Link, Alan Pauls, Gabriela Massuh, Juan José Becerra, Mariano Siskind, Daniel Guebel y María Fasce) una vez que la escena amorosa ha llegado a su fin, pero la estela que deja consta de varias figuras y de unas cuantas sensaciones. Por 
eso, además de interesarle a Ariza la figura del abandonado, le importan sus despliegues y contagios, como el ser que emigra (el que se va porque quiere), el que es arrojado fuera del sistema (el que se va porque lo echan), el que intenta construir un nuevo modo de mirar el futuro (cómo sobrevivir a una catástrofe), y el abandono como ética artística (cómo seguir escribiendo). Para esto, Ariza se apoya en un aparato teórico (Agamben, Blanchot, Barthes, Badiou, Benjamin y Bergson) que construye con precisión, rigurosidad y claridad, y que le sirve para sostener hipótesis contundentes.

La serie se arma porque se trata de novelas sobre el amor, porque todos los protagonistas fueron expulsados de la escena amorosa, porque todos son varones abandonados y porque son novelas escritas después de la gran crisis que azotó a la Argentina en 2001. Amor, crisis y abandono es la fórmula que se despliega para armar serie, para entablar lazos entre una generación de escritores que quizás se unen también por otros motivos. Aquí se muestra el momento exacto del desmoronamiento: ha sucedido una catástrofe y veamos qué hacer con los restos. El crack up lo llama Fitzgerald, el mal de tiempo le dice Alan Pauls en el prólogo a las obras de Fitzgerald. Hay alguien que no da más, que se desmorona, incapaz de pensar y hacer, exhausto, inerte, insensible, como congelado por una especie de estupor que lo invade todo. Gilles Deleuze se pregunta ¿qué pasó? ¿cómo llegué hasta acá? ¿quién me trajo? Esta es la escena que uno presencia cuando Ariza lee el abandono en esta serie de novelas. El abandono como catástrofe social y personal, como estructura frágil y vulnerable, como sacrificio, como escape y apuesta política, como debacle temporal y como ruina.

Dos son las figuras que entran en juego en una relación asimétrica: el abandonante que toma la decisión de irse, decisión inapelable e irreversible, y el abandonado que queda inmovilizado (Ariza lo define desde la etimología de la palabra amurar) en un espacio tiempo de ansiedad. Ha sucedido un evento catastrófico que viene de afuera, que sorprende, que irrumpe en el contexto amoroso para desestabilizar. Ese evento dura en el tiempo, un tiempo congelado que parece no pasar, pero que hay que dejarlo pasar. "Es imposible volver al pasado, es imposible salir del pasado.” ¿Cómo sobrevivir al abismo temporal del silencio que provoca el estallido? "No hay escapatoria del amor."

Los abandonados literarios se colocan en el umbral de la vida, entre el presente y el futuro, se quedan quietos pero desesperados. No hay proporción que pueda medir la desazón. Hay que soportar, y para hacerlo, Ariza entiende que hay que inventar. En el mal de tiempo, hay una ansiedad de relato que intenta llenar el vacío. "El abandonado recrea constantemente las historias de un pasado que sólo a él le pertenecen." La incertidumbre temporal deviene ansia de creación, le otorga espacio a la ficción. Si el tiempo no se mueve, que se mueva el relato. Las ficciones con las que Ariza arma una topología 
amorosa articulan lo íntimo y lo social a través de ciertos principios éticos que ponen en juego un modo de definir lo literario. En algunas, el abismo amoroso toma el calibre del terror a la página en blanco, la renuncia al amor es la renuncia a poder/seguir escribiendo. En otras, el abandono se escenifica en final apocalíptico en el que se representa el fin de lo conocido hasta hoy. En otras, el vivir sin amor se equipara al vivir sin estado, al desamparo y la intemperie como experiencias de un afuera total; o recurren al exilio, al irse para volverse imperceptible en una metamorfosis disolutoria. También algunos personajes ingresan al juego de conectarse con la propia vulnerabilidad hasta fragilizarse como ejercicio consciente de autoanálisis en el marco de las escrituras del yo.

El abandono cambia de forma, pero sus vestigios mantienen la potencia ética de semejante figura. Me interesa la lucidez de Ariza para definirla a través de una selección impecable de novelas. Me interesa mucho más que en el análisis específico de cada texto en particular, la literatura renueva su fuerza para seguir diciendo. Quiero decir que Ariza sale airoso del riesgo inminente de toda lectura de corpus en la que los textos quedan reducidos al problema tratado o a una red de similitudes. En este libro, la fórmula amor, crisis y abandono se sostiene teóricamente y es la literatura la que la hace subsistir. El foco está en la figura doliente, pero los textos continúan hablando por sí solos, constituyendo problemas propios y resaltando las más íntimas ambigüedades. 


\section{Referencias}

ARIZA, Julio. El abandono. Abismo amoroso y crisis social en la literatura argentina reciente, Rosario: Beatriz Viterbo, 2018.

DELEUZE, Gilles. “Porcelana y volcán”. In: La lógica del sentido. Buenos Aires: Paidós, 1989, p. 162-169.

; GUATTARI, Félix, “Tres novelas cortas o qué ha pasado”. In: Mil mesetas. Capitalismo y esquizofrenia. Valencia: Pre-textos, 2006, p. 197-211.

FITZGERALD, Scott. El crack up. Trad. Marcelo Cohen. Buenos Aires: Crackup, 2011.

PAULS, Alan. El mal de tiempo. In: FITZGERALD, Scott. El crack up. Trad. Marcelo Cohen. Buenos Aires: Crackup, 2011, p. 9-22.

Julia Musitano. Doctora en Letras por la Universidad Nacional de Rosario. Investigadora en el Consejo Nacional de Investigaciones Científicas y Técnicas (CONICET), profesora auxiliar de Análisis y Crítica II en la Universidad Nacional de Rosario y directora de la Revista Badebec. Publicó Ruinas de la memoria. Autoficción y melancolía en la narrativa de Fernando Vallejo, Un arte vulnerable. La biografía como forma junto a Nora Avaro y a Judith Podlubne, y ensayos en diversas revistas especializadas.

E-mail: musitanoj@gmail.com 